\title{
Base de Données d'Images Planétaires (BDIP): One Century of Planetary Images: 1870-1977
}

\author{
Pierre Drossart, Françoise Roques, Cyril Birnbaum \\ DESPA, Observatoire de Paris, section de Meudon, France \\ René Boyer, Eliane Neyvoz \\ DASOP, Observatoire de Paris, section de Meudon, France
}

The digitization of the planetary database of IAU has been performed, to give access to historical data in digital format. The database is constituted from the planetary photograph center collections, which was organized in 1961 at the request of the IAU (IAU conferences; Last reference: 1979, IAU Trans., XVIIA, 109). From this collection, 8473 images have been digitalized and are now accessible on line in a compressed format at the Web address: http://bdipwww.obspm.fr. The catalog information, including date and time of observations, and geometric configuration is completed for Jupiter and Saturn. The database contains plates recorded between 1870 and 1977:

Jupiter: 2715 images

Saturn: 357 images

Mars: 4661 images

Venus: 835 images

Mercury: 105 images

Cometary plates, recorded at Paris and Meudon Observatories between 1910 and 1975 are also being processed. The planetary database is recorded on 10 CDROM, with a total volume of about 5 Gbytes. Many scientific objectives, tedious to achieve from photographic plates, are more easily accessible from a digitized database. While many morphological studies have been performed in the past from the original plates, quantitative information like limb darkening studies, or the relative contrasts of belts and zones on Jupiter and Saturn, or the evolution of the polar caps on Mars can be studied more efficiently. Even if these objectives have often already been studied from photographic plates (SanchezLavega \& Gomez 1996), the digitized images can provide a new opportunity for a more quantitative work.

\section{References}

IAU conferences: Transactions of Commission 16 defining the rules of the Centre de Documentation Photographique (XI General Assembly, Berkeley; XII General Assembly, Hamburg; XIII General Assembly, Prague).

Sanchez-Lavega, A., \& Gomez, J. M. 1996, Icarus, 121, 1 